\title{
Exploring the prosociality domains of trust and cooperation, through single and cooperative digital gameplay in Path of Trust
}

\author{
Konstantinos C. Apostolakis ${ }^{1}$, Athanasios Psaltis ${ }^{1}$, Kiriakos Stefanidis ${ }^{1}$, \\ Kyriaki Kaza ${ }^{1}$, Spyridon Thermos ${ }^{1}$, Kosmas Dimitropoulos ${ }^{1}$, \\ Evangelia Dimaraki ${ }^{2}$, Petros Daras ${ }^{1}$ \\ ${ }^{1}$ Information Technologies Institute, Centre for Research and Technology Hellas, \\ Thessaloniki, Greece, \{kapostol, at.psaltis, kystefan, kikikaza, \\ spthermo, dimitrop,daras\}@iti.gr \\ ${ }^{2}$ Ellinogermaniki Agogi, Pallini, Greece, dimaraki@ea.gr
}

\begin{abstract}
Amidst an ongoing debate surrounding the traditional dichotomy of whether video games are good or bad for children, in this paper we present Path of Trust, a novel, prosocial game that aims at helping children understand the importance of teamwork and learn how and when to express trustworthiness. We have created a colorful, non-violent digital game, in which children aged 7-10 can be exposed to prosocial content and develop specific prosocial attitudes, such as cooperation and trustworthiness, driven by the fact that video games with prosocial content can be used to improve social interactions. The game was designed to maintain an attractive and engaging nature, which is usually associated with games that are often vilified within social circles in terms of being packed with tons of action and violence. We conducted two separate studies to test our game's modeling of prosocial behavior, which demonstrate the potential of the game as a tool for teaching important prosocial behavior to children.
\end{abstract}

Keywords: video games, prosocial video games, prosocial behavior;

\section{Introduction}

Current digital games targeting the education sector carry an unfortunate reputation among gamer communities in general. "Edutainment" is often mistakenly linked to low quality, as players feel such games fail to captivate their imagination. This fact leads to a significant blow to these games' effectiveness. Indeed, serious games can provide a very efficient means for skills acquisition, as they are usually defined in constrained environments that allow players to subliminally concentrate on the accomplishment of their task. In this respect, serious games categorized under the educational [1], [2], recreational [3] or mind exercising character [4], [5], [6], strive to achieve their goals with the use of proper structures, all while presenting an attractive package. Often however, this deliberately sacrifices the element of sheer enjoyment in favor of players achieving the desired progress [7]. In contrast to that, games developed purely for the entertainment industry tend to revolutionize society and culture, by offering engaging storylines, memorable characters and exciting game content. In many cases, such game titles have propelled the emergence of multibillion dollar franchises, whose protagonists are unanimously regarded among our age's popculture icons. Such games however also receive criticism, often stemming from their depiction of violence and desensitization. And truthfully, most of these modern multi-million unit selling game franchises popularly regarded as some of the best games of our time involve plots, which emphasize on violence. As can be seen in Table 1, four out of the top five highest scoring video games of all time are games in which physical violence is a core component of the actual gameplay. In fact, studies that explore the impact of game violence on players' general behavior suggest an existence of certain relations between game content and attitudes related to aggression [8], [9]. If we were to accept however, that exposure to violent games may breed anti-social and aggressive behaviors in minors, we should not overlook the similar potential of non-violent, 
"prosocial" games, in which helping and caring for others can positively affect the formation of a child's personality, assisting children in comprehending that trusting and exhibiting prosocial behaviors have long-term and well-grounded beneficial results.

Prosociality can be interpreted in many ways, and people are exposed to prosocial behaviors on many occasions during their everyday lives. In the Oxford English Dictionary [10], "prosocial" is defined as behavior which is positive, helpful and intended to promote social acceptance and friendship, while adhering to the moral standards accepted by an established social group. A simpler way to explain prosociality, is to define the concept as the behavior of helping others [11]. Prosociality is in itself a complex concept and is comprised of many core domains, which include empathy, social competence, emotional intelligence, trust, fairness, compassion, generosity and cooperation [12]. In this respect, studies showing the relationship between violent and continuous gameplay habits and anti-social behaviors should, and have been extended towards prosociality [13]. Already, strong findings towards this hypothesis are exhibited in related studies [14], [15]. Yet, only a few games exist wherein main characters model helpful and completely non-violent behaviors [3] [16], while the scope of prosociality is usually not intended. The latter rather usually manifests itself by chance, in an attempt to gear the game towards younger audiences, or groups of players, while the main intent is mostly fixed on providing pure entertainment, rather than useful life lessons.

Table 1.The top-10 highest scoring video games of all time, according to Metacritic.com review aggregator [17].

\begin{tabular}{c|c|c|c|c}
\hline Game Title & Platform & $\begin{array}{c}\text { Release } \\
\text { Year }\end{array}$ & $\begin{array}{c}\text { Metacritic } \\
\text { Score (out of } \\
\text { 100) }\end{array}$ & $\begin{array}{c}\text { Metacritic.com } \\
\text { User Score(out } \\
\text { of 10.0) }\end{array}$ \\
\hline The Legend of Zelda: Ocarina of Time & Nintendo 64 & 1998 & 99 & 9.2 \\
\hline Tony Hawk's Pro Skater 2 & Sony PlayStation & 2000 & 98 & 7.6 \\
\hline Grand Theft Auto IV & Sony PlayStation 3 & 2008 & 98 & 7.5 \\
\hline SoulCalibur & SEGA DreamCast & 1999 & 98 & 8.9 \\
\hline Grand Theft Auto IV & Microsoft XBOX 360 & 2008 & 98 & 7.9 \\
\hline Super Mario Galaxy & Nintendo Wii & 2007 & 97 & 8.9 \\
\hline Super Mario Galaxy 2 & Nintendo Wii & 2010 & 97 & 9.1 \\
\hline Grand Theft Auto V & Microsoft XBOX & 2014 & 97 & 7.9 \\
\hline Grand Theft Auto V & One & 97 & 8.2 \\
\hline
\end{tabular}

In this paper, we present Path of Trust (PoT), a digital game offering both single as well as multi-player co-operative gameplay that focuses on helping young children understand, and acquire prosocial skills necessary for developing positive relationships, understand the importance of teamwork and evaluate trustworthiness. Our goal is to promote prosocial skills that can help children appreciate and recognize the value of understanding other people's needs. More specifically, we focus on the skills of identifying the benefits of cooperation and expressing trustworthiness, by fabricating these concepts into core game mechanics which, as demonstrated through small-scale user studies held in schools, are capable of producing favorable gameplay experiences, while modeling and promoting prosocial behavior to children. Our target gamer population is comprised of children aged 7-10, i.e. age groups that benefit from developing a sense of accomplishment based upon self-control and school performance [18].

Dunn and Schweitzer define trust as "the willingness to accept vulnerability based upon positive expectations about another's behavior" [19]. It is commonly thought that trust is a fundamental quality for a society to function as a whole [20] [21]. In general, having one another's trust is vital to cooperation [22]; it is therefore important to have the skills necessary to communicate to others that one can be trusted and will make a good cooperation partner, as well as being able to tell who to trust in a given situation. It is important to note that any form of skills acquisition in the prosocial domain of trust should focus on children achieving and maintaining moderate levels of trust. As noted by Rotenberg et al. [23] children who hold very low or very high trust beliefs display a respective cynical or naïve orientation in comparison to a peer group, thus deviating from the norms and risking not only social exclusion from the group, but also a 
significant blow to self-perceived social acceptance and internalized maladjustment [23]. It is therefore important not only to promote trusting behavior whenever it is appropriate, but also prepare young children to deal with undesired behaviors from others as well. In this paper we will explain how this balance between trust and critical reasoning is considered.

More specifically, the remainder of this paper is organized as follows: Section 2 will deliver a psychological background of studies on the effects of violent and prosocial gameplay on social outcomes. Section 3 will present a brief history of games that have been examined in related studies and characterized as 'prosocial games', as well as provide examples of games which model some sort of prosocial moral code into their storylines. Section 4 will introduce our Path of Trust game in detail, and explain core game mechanics and narratives driving its prosocial nature. Section 5 offers a look on the user studies held in school environments, focusing particularly on children at the ages 7-10. Finally, Section 6 concludes with a discussion on interesting findings and future work.

\section{Impact of violent/prosocial gameplay habits on social outcomes}

The effect of violent or prosocial gameplay in terms of whether video games demonstrate a significant association with social outcomes has been the subject of debate within the scientific community. There have been several works addressing the controversial topic of game violence as a suggestive theme, i.e. whether violent video games increase aggression and aggression-related variables while simultaneously decreasing prosocial outcomes, whereas prosocial video games could have the opposite outcomes. A controversy further intensified by the 2011 Brown v. Entertainment Merchants Association (EMA) US Supreme Court ruling, which struck down a state of California law, which banned the sale of certain violent video games to children [24]. To make a fair assessment on the matter, researchers have published contradicting conclusions, with the group around Anderson and Bushman [16] [25] [26] [27], as well as Greitemeyer et al. [13] reporting evidence of a positive link between violent video games and aggression, while Ferguson's analyses questioned the existence of such a link [28] [29] [30]. As this question remains the subject of ongoing debate, prejudiced public outlooks on gamers and game developers in general will stem from the fact that playing video games (violent or not) is often vilified [13]. On a lighter note though, addressing the matter of prosocial video game play and its link to positive influences in social behavior, scientific research appears to converge to a common consensus, which indeed seems to cement that link [15] [31]. Gentile et al. [14], siding with the Anderson et al. scientific outlook, suggest causal impact of playing prosocial games on helpful behavior in a similar extent to violent games on hurtful behavior. Greitemeyer et al. [13] provide evidence that prosocial video game exposure increases helping behavior and decreases aggression. Similarly, Jerabeck \& Ferguson [31] have suggested that cooperatively playing violent video games (thus combining violence and the prosocial behavior of helping others in a video game) decreases aggressive behavior regardless of the depiction of violent content. The latter claim has been supported by other works, suggesting cooperative game play of violent video games counteract negative effects [32] and increase empathy [33]. These works draw upon Eron \& Huesmann [34], which dictates that aggression is antagonized by cooperation and empathy. As research throughout the years shows that gamer preferences lean heavily towards violent video games [35] [36] [37] [38] [39], Greitemeyer \& Oswald [15] highlight that video games with prosocial content could be used to improve social interactions, and moreover state the need of convincing the video games industry to develop prosocial video games, that are highly attractive to consumers.

\section{Prosocial games in the scientific literature}

In the scientific literature studying the social impact of digital games, specific titles are defined as "prosocial", usually as a means to differentiate them from games in which violence is the main theme. In this sense, games which occasionally model helpful behaviors are selected as candidates to draw connections between gameplay habits and players' real-life disposition for adopting helping behaviors, in a similar sense as violent games are often blamed for increased aggression. Gentile et al. [14] use specific examples of games and game levels, in which characters appear to model helpful behavior as opposed to fighting numerous enemies. In Chibi Robo, players attempt to earn Happy Points, corresponding to their families' happiness level, by cleaning up the house, 
helping in chores and completing everyday tasks. In Super Mario Sunshine, there's a specific level at which the player is tasked to clean an island of pollution in order to make its inhabitants happy and advance to the next level. Cartoonified aggressive behaviors common in the Super Mario game series (i.e. stomping on enemies to kill them) were excluded completely, in order to increase the impact of enacting prosocial behavior. Greitemeyer \& Oswald [15] categorized the games Lemmings and City Crisis as prosocial games. In the first game, the goal is to lead a group of creatures to the exit, preventing fatalities in the process. In City Crisis the goal is to promote the security of a city and save lives. The clear selection criteria for these games appear to be a complete (to the extent possible) absence of violence, and a recurring theme of helping and caring for others. Ferguson on the other hand [40], examines the concept of staging action-oriented, otherwise noted as violent, video games in prosocial contexts, considering player preferences towards games that feature violent themes, especially young male gamers [37] [38] [39], as a factor to argue on their usefulness in educational contexts. He argues that by taking advantage of the existing, popular first-person shooter format and applying this format for a prosocial purpose, its attractiveness can secure player attention, as well as increase the potential of achieving positive learning outcomes that are otherwise difficult to attain in other contexts. The author presents the first-person shooter Re-Mission as an example, where players take on the role of a microscopic robot injected into the bodies of cancer patients with the aim of blasting cancer cells, acknowledging how violent video game behavior can contribute to a greater good, simultaneously aiming at improving cancer knowledge and treatment adherence in teen and young adult cancer patients. Both sides appear to agree on the goal of the game being about the greater good, while whether the option to use in-game violence as a means to an end remains a subject of debate [13].

As previously stated in Section 2, prosociality in video games has mainly been studied with respect to modeling helpful behaviors [14], cooperation [32] and establishing empathic links [33], though the majority of games used in these studies incorporate these elements as a means of offering players multi-player entertainment-oriented outings. However, there have been virtually no studies involving specific games that target at teaching, or studying the effects of prosocial skills related to specific domains in prosociality, especially ones that concern trust, as a major factor of facilitating cooperative behavior. In the remainder of this paper we will present the design methodology for re-imagining a popular video game genre into providing a platform for which trust between players is essential to survive in the game. In the following Section, we will define the background and mechanics which constitute our game's main theme, which revolves around the concept of trusting in others and, as a result, identify the benefits of cooperation.

\section{Path of Trust game description}

As mentioned earlier in this paper, the concept of developing highly attractive video games featuring prosocial content has been stressed out by researchers in the field of psychology [15]. Towards this goal, this new market for prosocial games is expected to benefit from borrowing elements from succesful and highly attractive video games and re-imagining them within a prosocial context [40]. Our approach was to identify elements primarily associated with the entertainment games industry and re-adapt traditional game mechanics in a way that supports a prosocial context, delivering beneficial outcomes for players. Therefore, we set out to design a video game in which key elements include expressing trustworthiness and identifying the benefits of cooperation [11]. We chose the endless running games genre as a base for staging our prosocial game. Endless, or infinite running games are primarily platform games, in which players control characters who are constantly running through a procedurally generated, seamingly endless game world. The goal of these games is for players to either venture as far as possible, achieve longlasting time scores or collect specific items while avoiding others to increase their personal score. Common in all endless running games is the inevitable nature of the game over condition, caused by the "death" of the player character (though not necessarily associated in the games' storyline with the character actually dying in the game world), through mechanics that make the gameplay more challenging (introducing additional hazzards, faster screen scrolling, etc.) and less likely for players to succeed. Endless running games are among the most popular and attractive games in modern-day mobile game market, enjoying particular success in mobile platforms [41]. Furthermore, the limited set of controls required to play these games (usually involving means of administering directional input, with the occasional 'jump' or 'action' button) make them wellsuited for young children in the 7-10 target age group. In fact, in a recent report on exploring play and creativity in pre-schoolers' use of apps, the endless running game 'Temple Run' ranked 6th in 
the top ten list of app preferences, and was found to be easier for young children to complete than other games in the list [42]. In addition to their suitability for younger audiences, games within the genre are also quite easy to implement and stage within a non-violent setting and can effortlessly integrate a variety of input configurations (i.e., keyboard, mouse, controller, Kinect, etc.).

Our cooperative game's storyline features two daring adventurers, that have entered an old Egyptian pyramid in search for treasure while navigating through a maze-like structure, avoiding mummies and other hazards in the process. To accentuate the necessity of building a trusting bond between the two partners, the player who is controlling the character wandering around the dungeon corridors (henceforth referred to as the Muscle) is deprived of spatial awareness within the maze (i.e. the players can only see the area they are currently occupying), while their partner (referred to as the Guide) uses a top-down map view to navigate them safely through the maze without being caught. The Muscle player's sensory deprivation (i.e. affecting the player's ability to move from one place to another, as the correct way is not always obvious) during game world navigation mechanic [43] provides a means of heightening spatial immersion, by having the player maneuver through a game world, unaware of the size and depth of that world. The game uses this heightened immersion to provide an exciting game-play experience, where the player navigating through the 3D world is constantly in the thrill of what lurks around the next corner. By removing the sensory element of a mechanic such as Game World Navigation, we provide a platform for which trust between the Muscle player and the human/NPC Guide is essential to survive. If that trust is broken, the Muscle may either lose valuable time chasing useless items or worse, getting caught by one of the Mummies, which means both parties will not succeed. Towards a similar effect, the Guide's map in the game's multiplayer setting is concealed through a Fog of War mechanic [44], which will not allow the Guide to see more than one interconnected corridor ahead. Using fog of war in a cooperative multiplayer game can help build trust between both players; they both need to trust each other to progress in the game. The player being navigated must trust their partner to provide guidance away from danger, while the navigator must trust their partner to listen to directions.

It is obvious in the description above, that one player is to an extent deprived of the game world and the other has to rely on good memory in order to navigate both of them around. Players therefore are given distinct roles and different abilities and are free to make choices in which they set their own individual gains against the gains of the team, while at the same time trying to adhere to a set of mutual goals (i.e. not letting the player being navigated fall to one of the hazards in the dungeon, which would mean both players do not succeed). In this respect, we could not find any existing game in the endless running platform genre that provides a similar platform for which trust between both players is essential to survive in the game. Players however, must not be explicitly told to cooperate in order to win the game, lest the concept of adopting this behavior is diminished as a means to a reward. Instead, players are left to decide during gameplay if they shall work together to reap equal rewards or if they want to go out for themselves, endangering a spurious cooperation that might lead to both players' downfall. Our ultimate goal is for players to realize they can achieve far greater results when following a shared agenda. In our case, the benefits correspond to collecting treasure points, racing against time trying to collect as much as possible. Again, simply telling the players to cooperate will not yield the inception of a trusting bond between the players; therefore a competitive element is introduced in the form of unequal rewards [45] whenever a shared resource item is collected. With this mechanic, one player (e.g. the Muscle) is rewarded twice as much for collecting a treasure point than the other- both players are meant to realize the benefits of their role, as well as formulate a desire for re-routing resources based on the understanding of mutual benefits. Therefore, we allow the weaker party at the end of the bargain (e.g. the Guide, who always receives half as much points as the Muscle for collecting a treasure point) to be aware of when the opportunity to switch roles presents itself, by adding an additional, unavoidable item in the game: the Magic Portal. After players switch roles, so are the benefits re-routed. It is left up to the players to realize whether role-switching was necessary in an attempt to achieve a fair balance between player accumulated treasure points, or whether the Guide's direction was birthed out of pure greed (i.e. the player wants to keep playing as the Muscle to collect more points). This realization is most likely to lead to appropriate action in the future by both parties (for example, the player now playing as Guide trying to lead his/her partner to another portal, if they feel they were unjustly treated, while the player now playing as Muscle is more likely to ignore these directions).

A second thematic setting was established in a Christmas Edition of the game, included as an unlockable theme during the months November to January. In this version, the characters are replaced by Santa's elves following instructions on collecting toys for Santa's sleigh, while the 

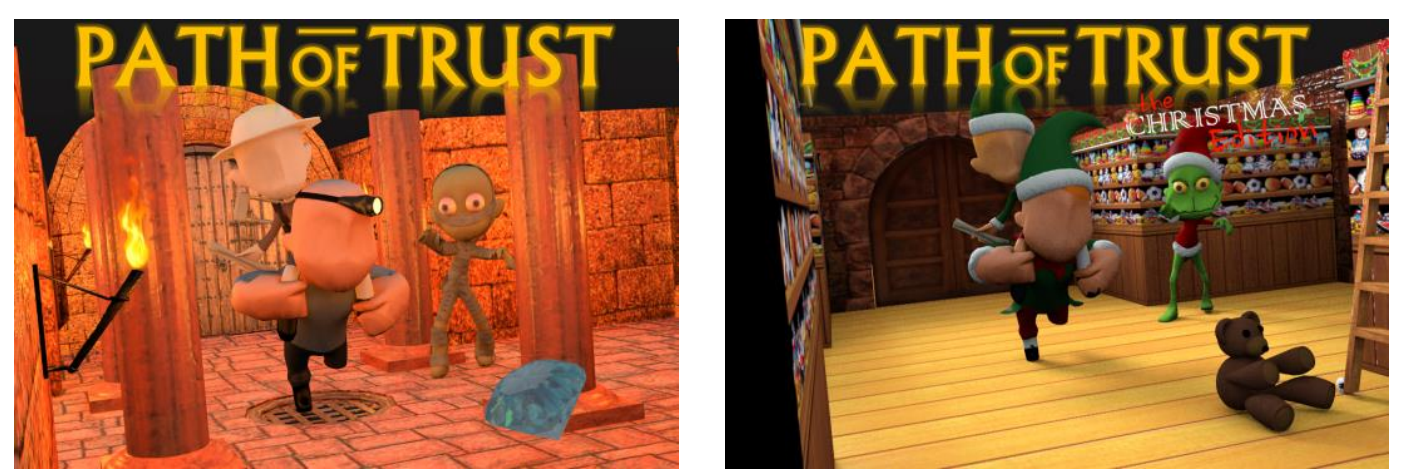

Figure 1. Path of Trust and Path of Trust: The Christmas Edition title screens. Different game assets are used in each version, to support the narrative background.

mummies have been replaced by the Grinch, attempting to steal Christmas. The two versions' title screens can be seen side by side in Figure 1 .

\subsection{Gameplay}

PoT is playable as a single player experience as well as a multi-player, cooperative game between two players. The basic premise of the game is that the characters navigate a maze, structured by junctions and corridors, as is shown in Figure 2. The dungeon corridors are populated by items, which can either be collected (upon touch) by the characters or need to be avoided. Some items only appear in the multi-player version of the game. The list of items in the game can be seen in Table 2. Junctions are areas in which the characters' path can be altered by following up to three different directions (turning left, right or continuing forward). As a narrative element in the PoT story, the Guide is only able to remember the contents of each corridor through faint memory, which is represented in the game by allowing the Guide (either human player or AI-driven NPC) to "peek" into the contents of only the adjacent rooms connected to the junction coming up next. This element is utilized both to model the NPC Guide's personality in the game's single player mode and to provide the basis for a memory-based mini-game designed to engage human players acting as the Guide in the multiplayer mode. The game furthermore features a time limit and a set of different endings for players to reach.

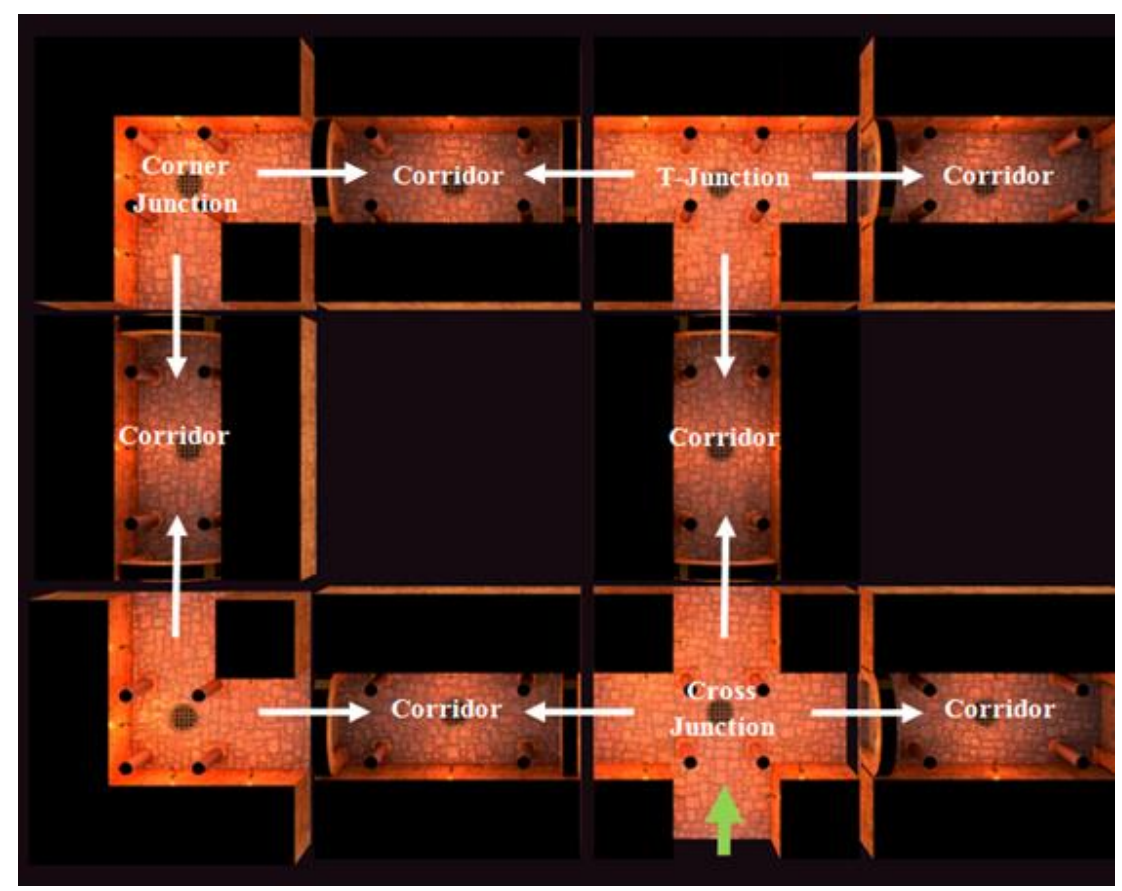

Figure 2. Junction and Corridor tile types making up the Path of Trust map maze. The bold green arrow indicates entry point for the characters. The white arrows indicate possible navigation paths. 
Table 2.Items in the Path of Trust game world.

\begin{tabular}{|c|c|c|c|}
\hline Item Name & Item Description & $\begin{array}{l}\text { Single } \\
\text { Player }\end{array}$ & $\begin{array}{l}\text { Multi- } \\
\text { player }\end{array}$ \\
\hline Sapphire/Teddy Bear & $\begin{array}{l}\text { Treasure Point, adds up the total tally of points collected by each } \\
\text { player in the single player cooperative scenario. } \\
\text { Treasure Point, adds up the total tally of points collected by the } \\
\text { human player in the single player competitive scenario. } \\
\text { Treasure Point, adds up the total tally of points collected by each } \\
\text { player in the multiplayer game mode. As mentioned before, } \\
\text { when the Muscle Player collects this Treasure Point, they get a } \\
+2 \text { on their tally, while the Guide player receives a }+1 \text { on their } \\
\text { own tally. }\end{array}$ & $\checkmark$ & $\checkmark$ \\
\hline Emerald/Toy Airplane & $\begin{array}{l}\text { Treasure Point, adds up the total tally of points collected by the } \\
\text { CPU player in the single player competitive scenario. }\end{array}$ & $\checkmark$ & \\
\hline Mummy/The Grinch & $\begin{array}{l}\text { Avoidable creatures living in the dungeon. They attempt to stall } \\
\text { players' progress by stealing their Treasure Points. When the } \\
\text { Muscle Player is captured by a Mummy/Grinch, both they as } \\
\text { well as their partner lose all combined or individually collected } \\
\text { Treasure Points. }\end{array}$ & $\checkmark$ & $\checkmark$ \\
\hline Portal & $\begin{array}{l}\text { Unavoidable items that allow two persons passing through them } \\
\text { at the same time to switch bodies. When the Muscle Player } \\
\text { passes through a Portal, he/she immediately becomes the Guide } \\
\text { Player and vice versa. No rewards or penalties are applied to the } \\
\text { players' total Treasure Points' tallies. }\end{array}$ & & $\checkmark$ \\
\hline
\end{tabular}

\subsubsection{Multiplayer game}

In multiplayer mode, the two players take on the role of the two adventurers who venture into the ancient tomb to uncover the loot hidden within. The two players are engaged in a multiplayer game where one is shown the 3D world as in Figure 4, while the other is shown a 3D top-down view of a 2D map as in Figure 3. Actual Path of Trust multiplayer gameplay is advanced according to the following descriptions:

Guide gameplay: As mentioned previously, the Guide is shown a top-down view of the common map in a 2D perspective, like in Figure 3. The Guide always gets to see up to three corridors ahead (left, forward, right, see Figure 3a). The Guide also gets to "peek" into the contents of each corridor for a small period of time that will henceforth be known as the Memory Window (Figure 3b). This way the Guide will know if the corridors to the left, right and forward contain Treasure, Mummies or Portals. After a limited number of seconds, the indicators will disappear and the player will have a small window (referred to as the Decision Window) in which to communicate his choice of direction to the Muscle. The possible actions are mapped to a direction of which 'left', 'right' and 'forward' can be possible candidates (Figure 3c). The Guide's indicators of treasure increment according to the splitting formula whenever the Muscle is passing through a room containing treasure. Of course it is in the interest of the Guide to sometimes lead the Muscle intentionally towards a Portal in order to swap bodies.

Muscle gameplay: The Muscle is shown a 3D view of the tomb scene in third-person view as depicted in Figure 4. The player can see the junctions and corridors, the two characters and the items (when inside a corridor). Once the Guide communicates his command, a direction indicator will be shown on the screen for a brief period of time (Figure 4a). During this time window, the Muscle player will be able to input his next move. The game indicates to the player that he/she is expected to make the choice by showing the indicator throughout the entire distance the characters have to travel before reaching the actual turning point (this will be henceforth referred to as the Decision Window). After the choice of direction has been made (Figure 4b), the characters will enter a corridor and have a limited room in which they can place their characters in order to touch treasure points or avoid Mummies. They can do that by moving the character to the left or right, during a limited time period determined by their speed (henceforth referred to as the Action Window, see Figure 4c). 
pag. 46

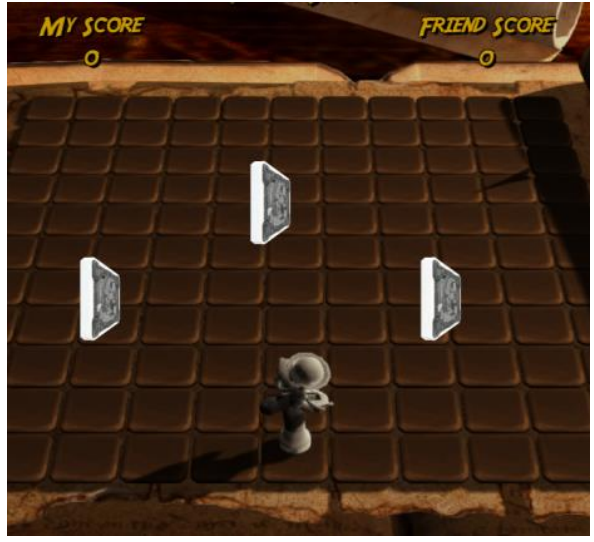

(a)

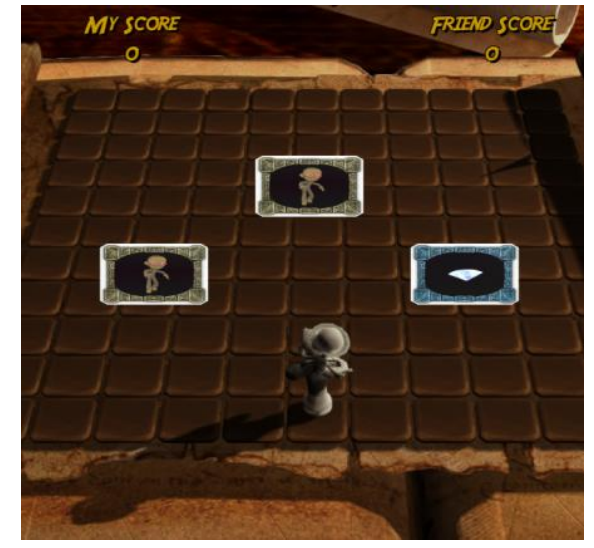

(b)

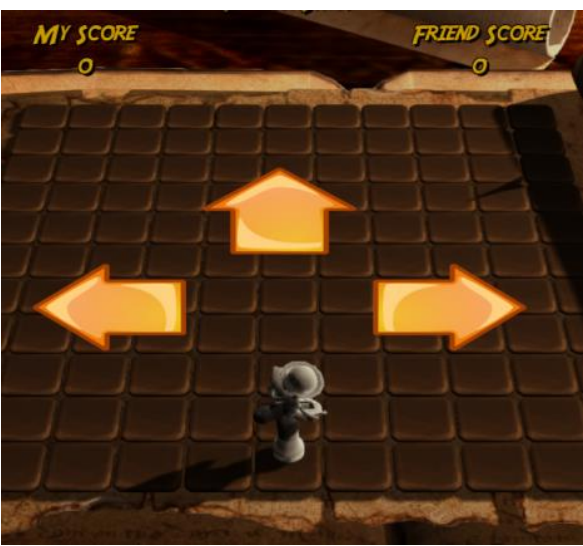

(c)

Figure 3. Guide player game loop.

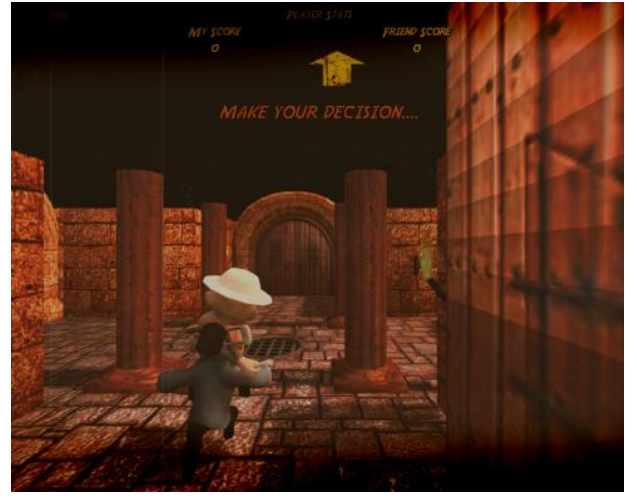

(a)

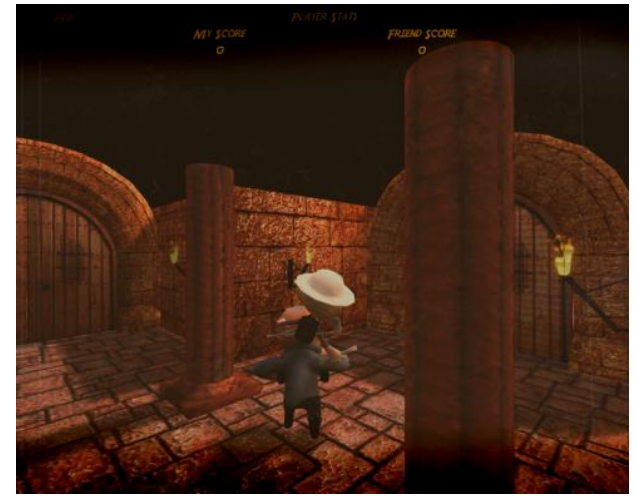

(b)

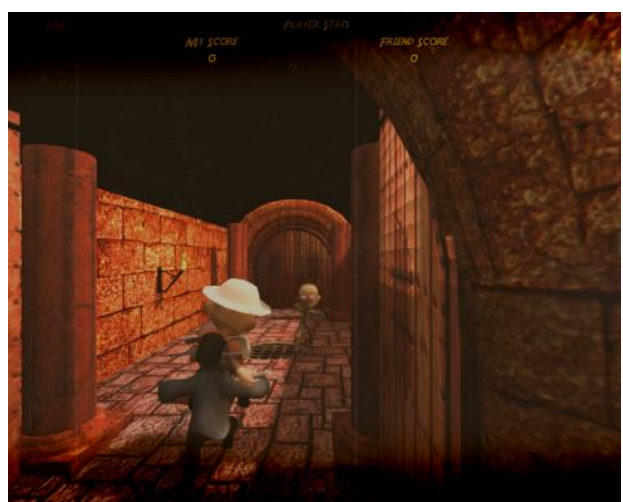

(c)

Figure 4.Muscle player game loop. 
Table 3. Example Simulation: Player 1 starts as Guide, Player 2 starts as Muscle. Players assumed to lead one another safely towards Treasure Points (TPs) while switching roles during Rounds 4, 8 and 10 to maintain a balance in their TP tally. End result is Victory for both players, as they reach their goal of 12 TPs each at the end of Round 11.

\begin{tabular}{l|c|c|c|c|c|c|c|c|c|c|c}
\hline Round & $\mathbf{1}$ & $\mathbf{2}$ & $\mathbf{3}$ & $\mathbf{4}$ & $\mathbf{5}$ & $\mathbf{6}$ & $\mathbf{7}$ & $\mathbf{8}$ & $\mathbf{9}$ & $\mathbf{1 0}$ & $\mathbf{1 1}$ \\
\hline $\begin{array}{l}\text { Player } 1 \\
\text { Role }\end{array}$ & $G$ & $G$ & $G$ & $M$ & $M$ & $M$ & $M$ & $G$ & $G$ & $M$ & $M$ \\
\hline $\begin{array}{l}\text { Player } 1 \\
\text { Award }\end{array}$ & +1 & +1 & +1 & +0 & +2 & +2 & +2 & +0 & +1 & +0 & +2 \\
\hline $\begin{array}{l}\text { Player } 1 \\
\text { Points }\end{array}$ & 1 & 2 & 3 & 3 & 5 & 7 & 9 & 9 & 10 & 10 & $\underline{\mathbf{1 2}}$ \\
$\begin{array}{l}\text { Player } 2 \\
\text { Role }\end{array}$ & $M$ & $M$ & $M$ & $G$ & $G$ & $G$ & $G$ & $M$ & $M$ & $G$ & $G$ \\
$\begin{array}{l}\text { Player 2 } \\
\text { Award }\end{array}$ & +2 & +2 & +2 & +0 & +1 & +1 & +1 & +0 & +2 & +0 & +1 \\
$\begin{array}{l}\text { Player 2 } \\
\text { Points }\end{array}$ & 2 & 4 & 6 & 6 & 7 & 8 & 9 & 9 & 11 & 11 & $\underline{\mathbf{1 2}}$ \\
\hline \begin{tabular}{l} 
Item \\
\hline
\end{tabular} & TP & $\mathbf{T P}$ & $\mathbf{T P}$ & $\mathbf{P}$ & $\mathbf{T P}$ & $\mathbf{T P}$ & $\mathbf{T P}$ & $\mathbf{P}$ & $\mathbf{T P}$ & $\mathbf{P}$ & $\mathbf{T P}$ \\
\hline
\end{tabular}

The game achieves synchronization between the two players by having the Guide's Memory Window take place during the Muscle's Action Window, a sensible solution, as the junction the Muscle is heading to is static and therefore the next three (two or one) adjacent corridors are already known. As the Muscle strives to collect or avoid the item inside the corridor, the Guide engages in a short memory game, which allows the player to choose towards which direction to go next. After exiting the corridor, the Muscle already has received the Guide's instruction, while the Guide's game world is being refreshed (i.e. oriented towards the direction the duo is now facing). The game is won if one of the characters reaches the appointed goal of treasure points. The game is designed in a way that an equilibrium is possible, i.e. there is potential for both players to cooperate in a way that both players can win at the same time (by collecting the final diamond, the Muscle player who currently has -2 treasure points from the goal and the Guide player who currently has -1 treasure points from the goal would win the game together). Table 3 presents an example of a possible game simulation in which the players win the game by collecting 12 diamonds each.

\subsubsection{Single player game}

In the single player case, the players take on the role of the Muscle character, while the Guide is controlled by the game's AI. This is a more direct way of facilitating lessons in the domain of trust, as the game is responsible for presenting players with a string of opportunities to adopt prosocial (trusting) behavior, and these can be easier controlled and monitored. Furthermore, the game is easier made "aware" of the potential outcomes of players' decisions, and therefore we can model several game scenarios based on the concept of trust, as well as control the NPC player's disposition towards genuinely wanting to help the human player in addition to helping itself. PoT therefore contains two single player scenarios, which slightly alter the game towards fulfilling a narrative purpose. In the "cooperation scenario" the two characters collect shared resources and have equal opportunity to access the same amount of points; one of the items described above grants points to both player and NPC character (i.e. Sapphire), while the others are either useless or potentially dangerous (i.e. encounter with a Mummy or Grinch). This scenario adheres more to the basic principles of endless running platform gameplay, as players attempt to collect as many valuables as they can, while avoiding hazards and wasting time on corridors with useless items. The "competitive" scenario on the other hand, slightly alters these rules, by eliminating the shared resources game mechanic as well as the useless nature of any of the items, by creating a situation in which one of the items is only attainable by the human player (i.e. the Sapphire or Teddy Bear) and another can only be claimed by the Guide (i.e. the Emerald or Toy Airplane). Therefore, only one character at a time is eligible to claim a treasure point to add to their tally, while the danger of stumbling upon a Mummy (or Grinch) remains constant. These scenarios are further enhanced by the AI controlling the Guide character with respect to its trustworthiness $\mathrm{f}$. The latter variable takes up values within the range $[0,1]$, with values close to 1 meaning the Guide is exhibiting a genuine intent in acting towards both his and the player's best interests and being completely trustworthy, while values close to zero indicate a Guide who has malevolent intent and will attempt to 
intentionally misguide the player towards reaching far greater benefits for itself. Modeling of these behaviors is achieved by influencing the Guide's automated procedure for deciding which direction to suggest to the player next, with its trustworthiness estimate. This feature has been included to adress the requirement of considering balance between trust and critical reasoning, i.e. preparing children to deal with both trustworthy as well as untrustworthy behavior. The aim is to promote the development of moderate levels of trust [23]. The following paragraphs will explain how this is implemented in the developed game.

In the cooperative scenario, the Guide will "peek" at the contents of up to three adjacent rooms and direct the player towards the shared resource with a probability given by its trustworthiness. If the shared resource is not among the available choices, the Guide will choose the least of two evils (i.e. wasting time on a corridor with a useless item or stumbling upon a Mummy or Grinch) with the same probability directing the final outcome. In the competitive scenario, each time one item is collected, the Guide will go through the process of determining the next item it will pursue in a similar manner, attempting to maintain a balance between its own points tally and the players, with a probability that is dictated by its trustworthiness value. The Guide will then "peek" into the contents of the three adjacent rooms and select its target item, or the item least hurting the duo's common agenda, weighted again by the same probability.

Scenarios are therefore characterized by the concept of the Guide's trustworthiness, and allow us to address issues in trusting behavior in terms of their relation to the BDT framework for Trust [46]: the cooperative scenario relates to the trust base of reliability. Unreliable Guides ( $f=0$ ) will usually point out to dungeon rooms with mummies, or useless items. The competitive scenario on the other hand relates to honesty. As the Guide now has a means of gathering more points than the player, dishonest Guides ( $f=0$ ) will point out to rooms where only they (e.g. the Guides) can collect items granting them points. If the difference in treasure points is in their favor, these Guides will occasionally point out to the direction of a Sapphire (if the alternative is for example, a Mummy), but they would rather direct the player towards a Mummy, if the player is too far ahead in points (as a result of not adhering to the Guide's directions). Reliable and honest Guides on the other hand ( $\mathrm{f}=1$ ), will always plan routes leading away from danger, trying to uphold a balance between theirs and the players' treasure points tally.

\section{Small scale user studies}

This Section will describe the objectives of each experimental study carried out, as well as the methodology adopted, the results of each study and finally the evaluation of the results. The two studies that are described in this Section were carried out in real/operational environments (classrooms) in Greece, focusing mostly on the proof of concept of the Path of Trust game.

\subsection{Multi-player study}

To test the multi-player aspects of our game and proof of concept in multi-player environments, we held a separate course of small-scale studies in a suburban private primary school in Greece. This study included a total of 16 students ( 4 boys and 12 girls) at the age group of 8-9 years old, who were asked to play the game. The purpose of this experimental study was to assess the children's understanding of the game and its mechanics, as well as their ability to use gesturedriven Natural User Interaction devices (i.e. Microsoft Kinect, Leap Motion Controller) to interact with the game.

\subsubsection{Methodology}

We used two mid-end laptops in this study, both of which were connected via LAN, with one of them hosting a PoT server to run the game. Each laptop was assigned a distinct NUI configuration (either using the Kinect, or Leap Motion Controller) and synchronization between the two was achieved via NTP. The game session required both players to be agnostic of their partner's identity, and therefore laptops were setup in adjacent classrooms. Physical communication between the participants was not feasible; instead players were only able to interact with one another using the in-game mechanisms of suggesting course and following/ignoring directions. Approximately, $62 \%$ of the participants had played some type of videogame before, while less than half had played games that involved any kind of interaction with other players. A brief description of the game's story and mechanics (i.e. explaining how characters are awarded treasure 
points for collecting diamonds according to their role, as well as how role-switching through magic portals was involved in order to for each player to get a chance playing with both characters during the same session), as well as an overview of the required gestures for each respective sensor configuration was presented to each participant separately, before the start of the session. In order to adhere to the school courses and ensure all participants would get an equal opportunity to play within the provided time slots, each session was assigned a time limit set at 5 minutes. Additionally, an endgame condition was defined in which the game was declared victorious for the player who first accumulated 10 treasure points. At the end of each session, the participants were asked to fill in short, open-ended questionnaires about the game, adjusted in language and presentation to the particular age group.

\subsubsection{Results}

Students generally rated their experience as rather enjoyable, and while assessments on the game challenge were varied, most students found the game to be relatively easy to play. Post-session free time Q\&A with the children on rating their experience showed that the game mechanics were suitable for our particular target age group, and that children generally found the concepts of being unequally rewarded for treasure points according to the character they played, as well as role switching to easy to understand. Regarding the participants' grasp of the true meaning of the game, the most common open answers involved the general concept of collecting treasure, players' collaboration, helping one another, and navigating the labyrinth. Interestingly, only one of the participants focused on the competitive element of collecting points to win. A similar trend in assessments was observed with regard to the question of what it takes to win in the game, where "collecting treasure" and "collaboration" were the most salient elements for students. Players were also asked to evaluate their relationship with the other player, in which, approximately $19 \%$ identified their partner as a pure adversary. Interestingly, $31 \%$ of the players acknowledged an element of competition, but still admitted to recognizing their partner as a team player, identifying the benefits they gained through cooperation. The remaining participants clearly identified the other player as a trustworthy cooperation partner. Finally, players were asked to evaluate the endgame result. In an interesting observation, ten out of sixteen players declared they felt that they had won or lost the game "as a team", despite some of the participants accumulating fewer points than their partner at the endgame. Players who made this statement noted their partner had benefited from their willingness to cooperate and therefore, felt like they too shared in their partner's success. Our findings in this study have previously been aggregated in [47].

Although these findings demonstrate measures in which PoT conveys the importance of teamwork to children within the age group 7-10, the measure of trust is a bit trickier, since children will play the game in their own way, presenting each other with opportunities to demonstrate trusting behavior that are not easily measurable or directly observable. Therefore, a second set of studies was planned as a follow-up work, to demonstrate PoT's capability for conveying and promoting the values of expressing trustworthiness.

\subsection{Single Player Study}

We conducted the aforementioned second set of experiments at a Northern Greece public primary school on 21st December 2015. Due to the date's proximity with the Christmas break, players were exposed to the Christmas Edition of the game (see Section 4). The purpose of this study was to establish how players would assess the NPC Guide's honesty, therefore, we chose the competitive single player scenario, in which the NPC Guide was shown being selected out of a bunch of 5 possibilities. 18 children aged 10 years old participated in this study.

\subsubsection{Methodology}

For the experiment settings, we used two PCs; a desktop PC that hosted the PoT server and was employed with the installed native client for gameplay with the Kinect for Xbox One sensor, as well as a personal laptop with no traces of the PoT front-end or backend installed, that was used for gameplay with the keyboard via the standard HTML interface. The laptop was connected with the game server via LAN and was synchronized using NTP synchronization. A short demo of the game with a brief description of the game story and mechanics of the single player version were shown to participants before playing. We specifically pointed out that the game's purpose was "to collect as many gifts as possible for Santa's sleigh", but did not specify that this could only be achieved by trusting in the NPC Guide, on whose directions' the players had to base so as to 
navigate in the virtual world of the game. This omission was intentional; its purpose was to examine if the participants would grasp the meaning of the game, understanding that it would be beneficial for them to trust in the NPC, who's AI was set to the " $100 \%$ trustworthy" setting $(f=1)$. After the demo session, the 18 participants played in turn one game session with the Kinect configuration and another one with keyboard configuration. The purpose of having these two sessions was to evaluate the difference in children's gameplay experience with respect to the engagement factor, between traditional game (keyboard) and natural game interaction (Kinect). After playing, the participants were asked to answer a questionnaire with two different parts; the first part consisted of questions targeted to evaluate player's engagement and overall game experience using the Game Engagement Questionnaire (GEQ) [48], while the second part contained questions concerning the game's purpose and a self-assessment of the trust that the player exhibited during playtime (Appendix A). Results would then be aggregated for both parts using the measurement approach of the GEQ, shown in Figure 5, demonstrating how answers to items in the questionnaire correspond to lower or higher engagement scores. N, M, and Y symbols displayed in the Figure refer to "No", "Maybe", and "Yes", respectively to each question displayed on the right. The easiest items to agree with are associated with immersion and presence, respectively, and the more difficult items to agree with were associated with flow and absorption, respectively [48]. One person in our user study coordination team was assigned to provide help and support to children with regards to answering any questions they might have about the queries present in the questionnaire (orally explaining, where needed, the meaning of each written question). The questions on trust were designed in order to appraise the players' understanding of the goal of the game, assessment of perceived honesty of the NPC Guide, as well as the players' opinion on their own competence.

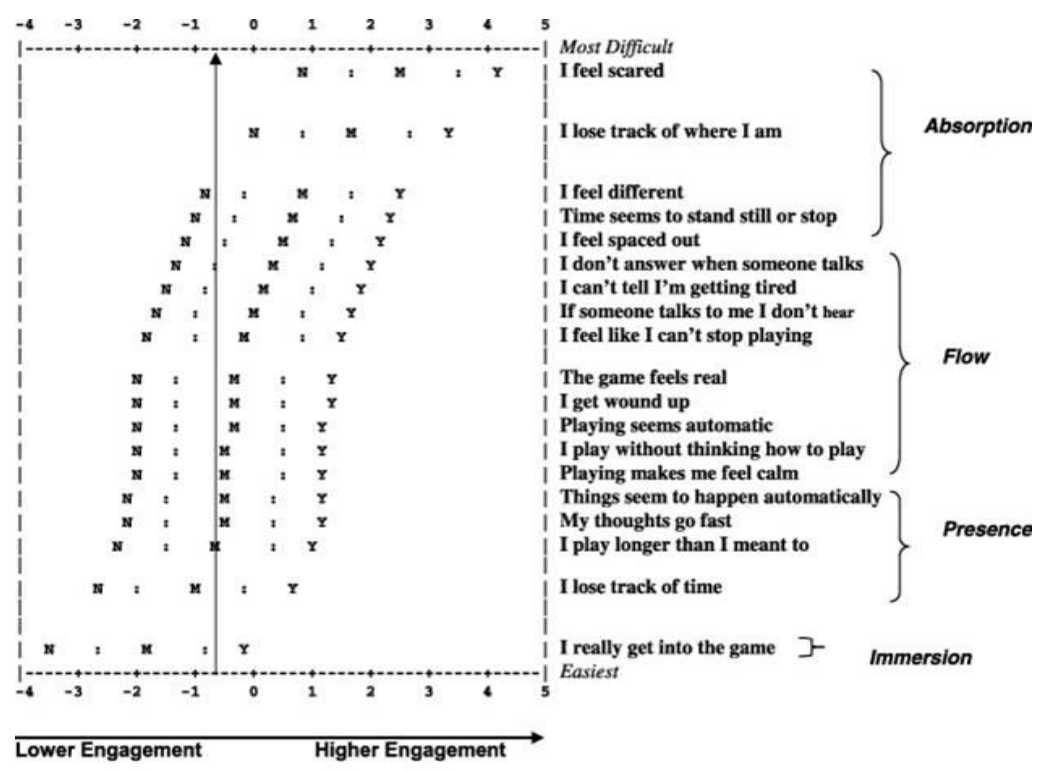

Figure 5. GEQ measurement approach [48].

\subsubsection{Results}

$83 \%$ of the children who played the game managed a balanced game ending, having collected the same number of toys as their NPC partner. $72 \%$ of the players responded they felt that picking upan equal amount of toys with their Guide partner was the best possible result, while $22 \%$ would have themselves collecting more toys than the Guide. When told that the original intention of the game (e.g. Santa's mission) was for the players to collaborate with their Guide and collect an equal share of toys, $94 \%$ of the players felt they did a good job. The players' self-assesment in their exhibited trusting behavior taking into account the questionnaire presented in Appendix A can be seen in Figure 6. When asked about their Guide's honesty, only 6\% of the players felt the Guide was not being very honest, and that most of the time, the Guide was suggesting wrong directions. An $11 \%$ of the players felt that the Guide was intentionally misleading them, and $17 \%$ did not get the feeling that the Guide wanted them to collect an equal number of points. When asked whether they felt they made the right decision - not following the Guide's directions on a 5-point Likert scale, out of the $39 \%$ of participants who admitted -that they had not followed the Guide's directions every single time, $17 \%$ felt they were always wrong for not following a given direction 


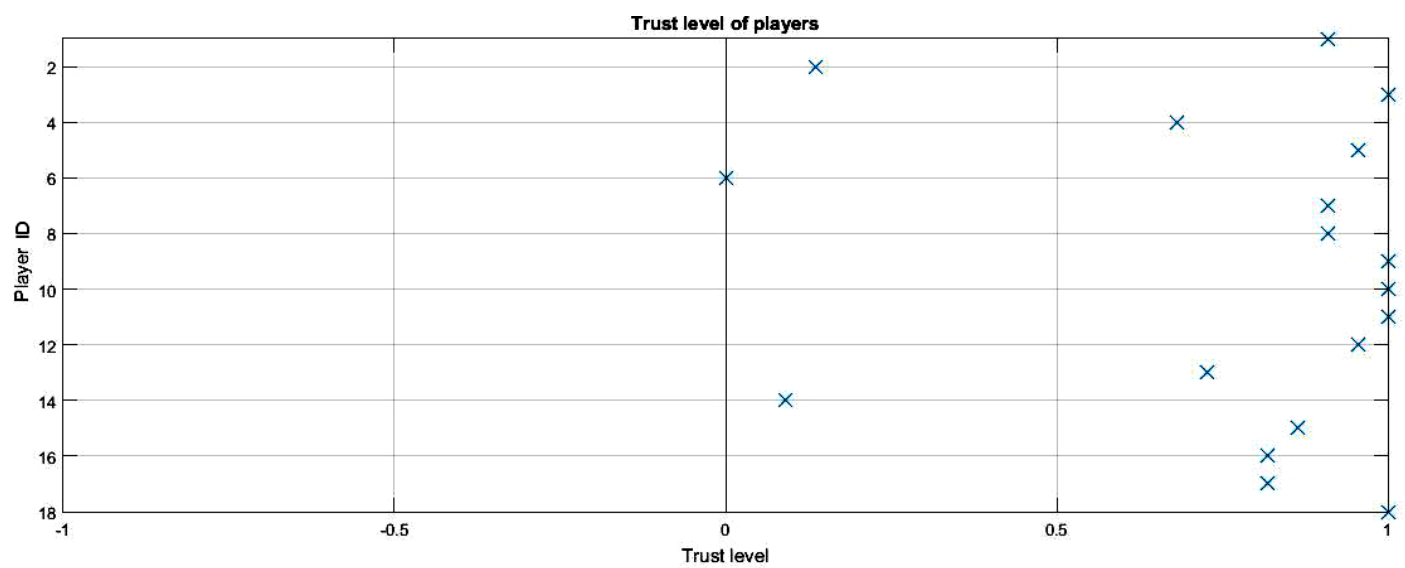

Figure 6. Players' self-assessment distribution in the prosociality domain of Trust.

followed by an $11 \%$ who strongly felt the same way and another $6 \%$ who were indifferent. When asked whether they would select the exact same Guide to cooperate in another mission for Santa on a 5-point Likert scale, $83 \%$ of the participants would definitely cooperate with that specific Guide again, while the remaining $17 \%$ would probably do so as well. On justifying these answers, $72 \%$ of the participants felt they knew they could trust in this particular Guide 100\%, while another $22 \%$ knew the Guide was trustworthy but possibly not trustworthy enough for this particular task. The remaining percentage was not entirely sure whether the Guide was trustworthy at all. No participant felt the Guide was definitely untrustworthy. Our findings in this study have been aggregated in Figure 7.

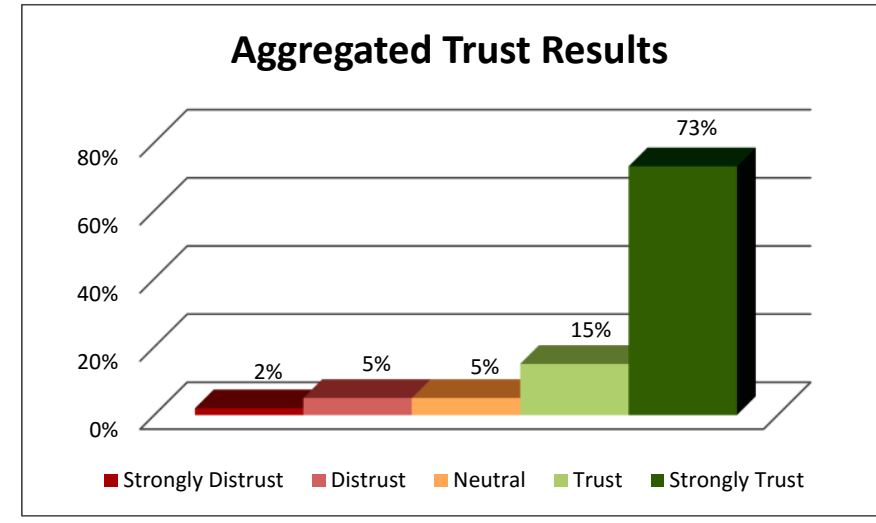

Figure 7. Aggregated results with respect to the players' self-assessment in the prosociality domain of Trust.

As can be seen in the aggregated results, an approximate $88 \%$ of the participants demonstrated the desired trusting skills, while a single participant (boy) demonstrated an outlying behavior, by refusing to trust in a Guide who was clearly pointing him in the right direction. Therefore, these results show that PoT could potentially also be utilized in the classroom to identify and support children at risk of social exclusion due to them demonstrating trust-related issues within the game world, although that claim should be scientifically verified in future work. On assessing the players' level of engagement, the GEQ answers were scored as shown in Figure 5. The engagement score of each player was calculated as the mean value of all scores. As it is depicted in Figure 8, 16 out of 18 players had scored between 0 and 1, indicating a mean engagement level, while only 2 players had a score slightly below zero. The mean engagement score of all players is 0.356 , which places PoT within the Flow category, indicating that our game received positive reception from gamers. Improving this measurement by adapting the game's speed and challenge level to match players' ability, as well as adding additional player actions (such as jumping over, and ducking under obstacles when inside the Corridors, especially utilizing the Kinect NUI to maximize bodily engagement of users while playing the game) will be considered in the future. 


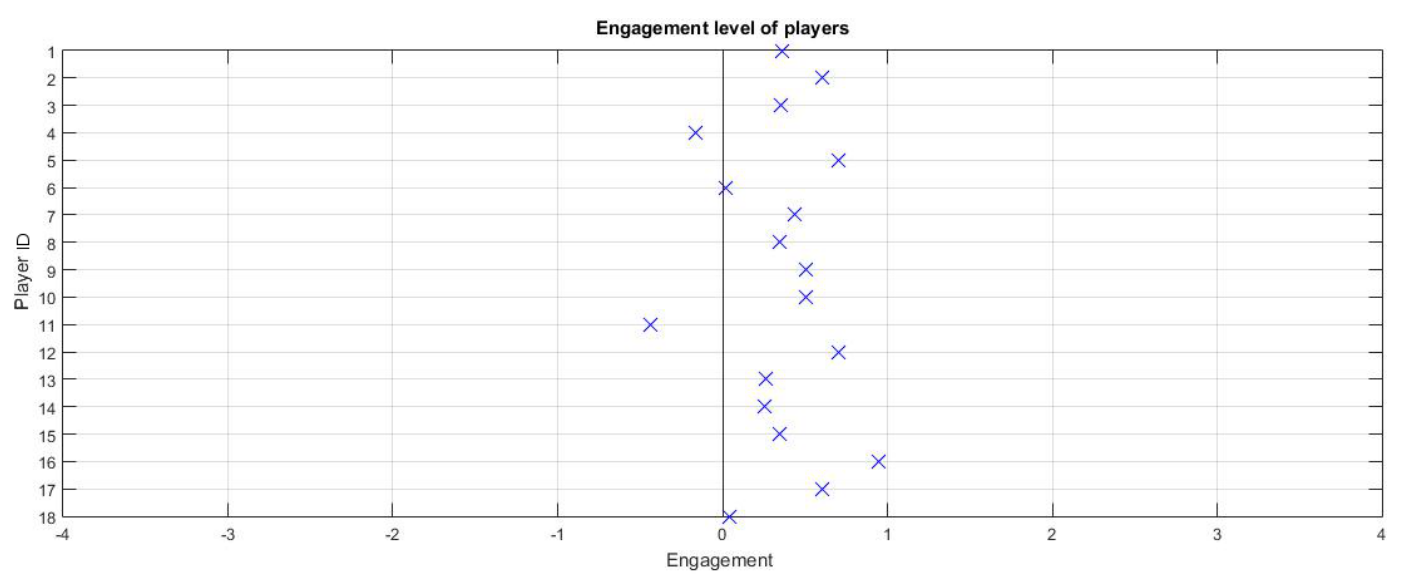

Figure 8. Player individual engagement score, as a result of the GEQ answers.

\subsection{Discussion}

These results demonstrate PoT's potential utility as a game towards delivering lessons in the prosocial domain of trust with respect to children maintaining moderate levels of trust [23]. This means that prosocial games geared towards promoting a balance between trusting behavior and critical reasoning need to consider within their game design elements which will help children understand the consequences of being too trusting (naïve) with strangers, or people who have clearly demonstrated a lack in trustworthiness in the past. Also, children should be taught to be more trusting towards those that have proven to deserve it. This can be done within the PoT context by providing real-time adaptation mechanisms designed to give feedback to the player, by replacing for example items inside Corridor tiles as a response to player choices, followed by praise or corrective feedback: if trusting in a Guide's directional input is the desired outcome (i.e. $f$ $=1$ ) at any given time during a crossroads Junction, players could be rewarded with Treasure Points whenever they adhere to the Guide's instructions, or, in case of a cynical approach, they could be reminded via text, or audio message that untrust and distrust should be reconsidered, complementary switching a potential reward item with an enemy. Similarly, if the Guide's trustworthiness $\boldsymbol{f}$ is deliberately set low at the start of a game session by a teacher, players should receive similar forms of in-game corrective feedback for being more cautious when dealing with undesired behaviors as opposed to being naïve. These elements provide a well-grounded foundation for future work on the game by incorporating such adaptation mechanisms. Furthermore, studying the long-term benefits gained from playing the game, as well as the effects on social outcomes over the course of multiple sessions is a logical next step towards validating the strong potential of a new market for prosocial games in teaching important social behavior to children.

\section{Conclusions}

In this paper we presented a prosocial game that models prosocial in-game character behavior addressing the core prosociality domain of trust, as well as promotes the importance of teamwork. The resulting Path of Trust game was then tested as a means to affect social outcomes on young children being exposed to the game content and gameplay. We conducted two separate user studies to test the ideas and mechanics behind the PoT gameplay in both single as well as multiplayer game scenarios. Our results with children within the age group 7-10, validated that the proposed PoT game is generally positively received in terms of being fun and exciting, as it features a thoroughly thought out storyline and characters, as well as familiar gameplay elements that children can easily associate with the games they play at home. Furthermore, our findings suggest that PoT is well suited to provide lessons in the prosocial domain of trust to children in the single player case, while the benefits of cooperation are made more salient to players when playing the game in a multi-player session along with a classmate. Our studies demonstrate that playing PoT reserves a great potential for observing causal impact on children's prosocial behavior [14], especially in the domain of trust, for which related scientific literature is currently lacking study and evidence. Our results furthermore showed that PoT can be a useful (and potentially powerful) teacher tool, as a means to identify students at risk of social exclusion; by monitoring playtime and 
gamer decisions throughout a single game session, they might be able to identify children demonstrating difficulties in their ability to trust in others, and as a result face challenges in facilitating helping behavior in the game- such difficulties may hinder students from fulfilling their potential for academic achievement.

Through the activities described in this paper, we have identified, and will thus work towards further focusing our efforts on providing real-time in-game feedback to players in accordance to their decisions and behavior during gameplay, via adaptation routines which will be based on sophisticated computational models that are capable of measuring trust values [49]. This will aim at solidifying consistency of the PoT game outcomes with players' prosocial behavior, especially within classroom environments. The existence of connections between playing the PoT game and adopting a self-regulated, intelligent trusting behavior (i.e. neither naïve, untrusting or distrusting), as well as links to social inclusion and improvement in academic achievement will also be studied as part of future work in this respect.

\section{Acknowledgement}

This work has received funding from the EU Horizon 2020 Framework Programme under grant agreement no. 644204 (ProsocialLearn project). The authors would like to thank all educational staff for their assistance and cooperation during the user studies.

\section{References}

[1] Dostál, J., "Educational software and computer games-tools of modern education”, J. Technol. Inf. Educ, 1, 24-28, 2009.

[2] McClarty, K. L., Orr, A., Frey, P. M., Dolan, R. P., Vassileva, V., \& McVay, A., "A literature review of gaming in education", Gaming in education, 2012.

[3] Anderson, C. A., Gentile, D. A., \& Dill, K. E., "Prosocial, antisocial, and other effects of recreational video games", Sage Publications, Inc, 2012.

[4] Baniqued, P. L., Kranz, M. B., Voss, M. W., Lee, H., Cosman, J. D., Severson, J., et al., "Cognitive training with casual video games: points to consider", Front. Psychol, 4, 1010, 2013.

[5] Nouchi, R., Taki, Y., Takeuchi, H., Hashizume, H., Nozawa, T., Kambara, T., et al., "Brain training game boosts executive functions, working memory and processing speed in the young adults: a randomized controlled trial”, PloS one, 8(2), e55518, 2013. http://dx.doi.org/10.1371/journal.pone.0055518

[6] Owen, A. M., Hampshire, A., Grahn, J. A., Stenton, R., Dajani, S., Burns, A. S., et al., "Putting brain training to the test", Nature, 465(7299), 775-778, 2010. http://dx.doi.org/10.1038/nature09042

[7] Buday, R., Baranowski, T., \& Thompson, D., "Fun and games and boredom", Games for Health Journal, 1(4), 257-261, 2012. http://dx.doi.org/10.1089/g4h.2012.0026

[8] Anderson, C. A., \& Bushman, B. J., "Human aggression. Psychology", 53(1), 27, 2002. http://dx.doi.org/10.1146/annurev.psych.53.100901.135231

[9] Anderson, C. A., Gentile, D. A., \& Buckley, K. E., "Violent video game effects on children and adolescents", New York: Oxford University Press, Vol. 10, 2007. http://dx.doi.org/10.1093/acprof:oso/9780195309836.001.0001

[10] "Oxford: Oxford university press", Oxford English Dictionary, 1989.

[11] Penner, L. A., Dovidio, J. F., Piliavin, J. A., \& Schroeder, D. A., "Prosocial behavior: Multilevel perspectives", Annu. Rev. Psychol., 56, 365-392, 2005. http://dx.doi.org/10.1146/annurev.psych.56.091103.070141

[12] Vuillier, L., \& Cook, C., "ProsocialLearn: D2.1 User requirements", 2015.

[13] Greitemeyer, T., \& Mügge, D. O., "Video games do affect social outcomes a meta-analytic review of the effects of violent and prosocial video game play", Personality and Social Psychology Bulletin, 0146167213520459, 2014. http://dx.doi.org/10.1177/0146167213520459

[14] Gentile, D. A., Anderson, C. A., Yukawa, S., Ihori, N., Saleem, M., Ming, L. K., et al., "The effects of prosocial video games on prosocial behaviors: International evidence from correlational, longitudinal, and experimental studies", Personality and Social Psychology Bulletin, 2009. http://dx.doi.org/10.1177/0146167209333045 
[15] Greitemeyer, T., \& Osswald, S., "Effects of prosocial video games on prosocial behavior", Journal of personality and social psychology, 98(2), 211, 2010. http://dx.doi.org/10.1037/a0016997

[16] Anderson, C. A., \& Bushman, B. J., "Effects of violent video games on aggressive behavior, aggressive cognition, aggressive affect, physiological arousal, and prosocial behavior: A metaanalytic review of the scientific literature", Psychological science, 12(5), 353-359, 2001. http://dx.doi.org/10.1111/1467-9280.00366

[17] Metacritic. (n.d.)., "High Scores", Retrieved March 10, 2016, from Metacritic.com: http://www.metacritic.com/browse/games/score/metascore/all/all/filtered?sort=desc

[18] Matysiak, S. A., \& Soute, I., "Support of social skill development in children age 7-10 through technologyaided game", Wydawnictwo PJWSTK, 2010.

[19] Dunn, J. R., \& Schweitzer, M. E., "Feeling and believing: the influence of emotion on trust", Journal of personality and social psychology, 88(5), 736, 2005. http://dx.doi.org/10.1037/0022-3514.88.5.736

[20] O'Hara, K., “Trust: from Socrates to spin”, Icon Books, 2004.

[21] Uslaner, E. M., "The moral foundations of trust", Cambridge University Press, 2002. http://dx.doi.org/10.1017/CBO9780511614934

[22] Jones, G. R., \& George, J. M., "The experience and evolution of trust: Implications for cooperation and teamwork", Academy of management review, 23(3), 531-546, 1998.

[23] Rotenberg, K. J., Boulton, M. J., \& Fox, C. L., "Cross-sectional and longitudinal relations among children's trust beliefs, psychological maladjustment and social relationships: are very high as well as very low trusting children at risk?", Journal of abnormal child psychology, 33(5), 595-610, 2005. http://dx.doi.org/10.1007/s10802-005-6740-9

[24] Ferguson, C. J., "Violent video games and the Supreme Court: lessons for the scientific community in the wake of Brown v. Entertainment Merchants Association", American Psychologist, 68(2), 57, 2013. http://dx.doi.org/10.1037/a0030597

[25] Anderson, C. A., "An update on the effects of playing violent video games". Journal of adolescence, 27(1), 113-122, 2004. http://dx.doi.org/10.1016/j.adolescence.2003.10.009

[26] Anderson, C. A., Carnagey, N. L., Flanagan, M., Benjamin, A. J., Eubanks, J., \& Valentine, J. C., "Violent video games: Specific effects of violent content on aggressive thoughts and behavior", Advances in experimental social psychology, 36, 200-251, 2004. http://dx.doi.org/10.1016/S0065-2601(04)36004-1

[27] Anderson, C. A., Shibuya, A., Ihori, N., Swing, E. L., Bushman, B. J., Sakamoto, A., et al., "Violent video game effects on aggression, empathy, and prosocial behavior in eastern and western countries: a meta-analytic review", Psychological bulletin, 136(2), 151, 2010. http://dx.doi.org/10.1037/a0018251

[28] Ferguson, C. J., "Evidence for publication bias in video game violence effects literature: A meta-analytic review", Aggression and Violent behavior, 12(4), 470-482, 2007. http://dx.doi.org/10.1016/j.avb.2007.01.001

[29] Ferguson, C. J., "The good, the bad and the ugly: A meta-analytic review of positive and negative effects of violent video games", Psychiatric Quarterly, 78(4), 309-316, 2007. http://dx.doi.org/10.1007/s11126-007-9056-9

[30] Ferguson, C. J., \& Kilburn, J., "The public health risks of media violence: A meta-analytic review", The Journal of pediatrics, 154(5), 759-763, 2009. http://dx.doi.org/10.1016/j.jpeds.2008.11.033

[31] Jerabeck, J. M., \& Ferguson, C. J., "The influence of solitary and cooperative violent video game play on aggressive and prosocial behavior", Computers in Human Behavior, 29(6), 2573-2578, 2013. http://dx.doi.org/10.1016/j.chb.2013.06.034

[32] Greitemeyer, T., Traut-Mattausch, E., \& Osswald, S., "How to ameliorate negative effects of violent video games on cooperation: Play it cooperatively in a team", Computers in Human Behavior, 28(4), 1465-1470, 2012. http://dx.doi.org/10.1016/j.chb.2012.03.009

[33] Greitemeyer, T., "Playing video games cooperatively increases empathic concern", Social Psychology, 2013. http://dx.doi.org/10.1027/1864-9335/a000154

[34] Eron, L. D., \& Huesmann, L. R., "The relation of prosocial behavior to the development of aggression and psychopathology", Wiley, 1984.

[35] Buchman, D. D., \& Funk, J. B., "Video and computer games in the '90s: children's time commitment and game preference", Children today, 24(1), 12, 1996.

[36] Dill, K. E., Gentile, D. A., Richter, W. A., \& Dill, J. C., "Violence, sex, race and age in popular video games: A content analysis", In E. Cole \& J. Henderson Daniel (Eds.), Featuring 
females: Feminist analyses of the media. Washington, DC:American Psychological Association, 2005. http://dx.doi.org/10.1037/11213-008

[37] Lenhart, A., Kahne, J., Middaugh, E., Macgill, A. R., Evans, C., \& Vitak, J., "Teens, video games, and civics: teens' gaming experiences are diverse and include significant social interaction and civic engagement", Pew internet \& American life project, 2008.

[38] Olson, C. K., "Children's motivations for video game play in the context of normal development", Review of General Psychology, 14(2), 180, 2010. http://dx.doi.org/10.1037/a0018984

[39] Olson, C. K., Kutner, L. A., Warner, D. E., Almerigi, J. B., Baer, L., Nicholi, A. M., et al., "Factors correlated with violent video game use by adolescent boys and girls", Journal of adolescent health, 41(1), 77-83, 2007. http://dx.doi.org/10.1016/j.jadohealth.2007.01.001

[40]Ferguson, C. J., "Blazing angels or resident evil? Can violent video games be a force for good?", Review of General Psychology, 14(2), 68, 2010. http://dx.doi.org/10.1037/a0018941

[41] Purchese, R., "Temple Run 2 is the fastest-spreading mobile", Eurogamer: http://www.eurogamer.net/articles/2013-02-01-temple-run-2-is-the-fastest-selling-mobilegame-ever, 2013.

[42] Marsh, J., Plowman, L., Yamada-Rice, D., Bishop, J. C., Lahmar, J., Scott, F., . . . others. (2015). Exploring play and creativity in pre-schoolers' use of apps: Final project report. Sheffield: University of Sheffield. www.techandplay.org.

[43] Finnegan, D. J., Velloso, E., Mitchell, R., Mueller, F., \& Byrne, R., "Reindeer \& wolves: exploring sensory deprivation in multiplayer digital bodily play", Proceedings of the first ACM SIGCHI annual symposium on Computer-human interaction in play (pp. 411-412). ACM, 2014. http://dx.doi.org/10.1145/2658537.2661309

[44] LeBlanc, M., "Tools for creating dramatic game dynamics", The game design reader: A rules of play anthology, 438-459, 2006.

[45] Brams, S. J., Jones, M. A., \& Klamler, C., "Proportional pie-cutting", International Journal of Game Theory, 36(3-4), 353-367, 2008. http://dx.doi.org/10.1007/s00182-007-0108-z

[46] Rotenberg, K. J., "The conceptualization of interpersonal trust: A basis, domain, and target framework", Interpersonal trust during childhood and adolescence, 8-27, 2010.

[47] Apostolakis, K. C., Kaza, K., Psaltis, A., Stefanidis, K., Thermos, S., Dimitropoulos, K., Dimaraki, E., \& Daras, P., "Path of Trust: A prosocial co-op game for building up trustworthiness and teamwork", Games and Learning Alliance: Fourth International Conference, GALA 2015, Rome, Italy, December 9-11, Revised Selected Papers. Springer. To appear, 2015.

[48] Brockmyer, J. H., Fox, C. M., Curtiss, K. A., McBroom, E., Burkhart, K. M., \& Pidruzny, J. N., "The development of the Game Engagement Questionnaire: A measure of engagement in video game-playing”, Journal of Experimental Social Psychology, 45(4), 624-634, 2009. http://dx.doi.org/10.1016/j.jesp.2009.02.016

[49] Marsh, S. P., "Formalising trust as a computational concept", University of Stirling, 1994. 
1) Santa has assigned to you the task of collecting toys for his sleigh. Which of the following game endings did you achieve?
a) The Guide collected more toys than I did.
b) I collected more toys than the Guide did.
c) We had both collected the same amount of toys.

2) Which result do you believe was better for Santa?
a) That the Guide should have collected more toys than I did.
b) That I should have collected more toys than the Guide did.
c) That we both should have collected the same amount of toys.

3) Santa told us, that he expected from both you and the Guide to collect about the same amount of toys each. Now that you know that, do you believe you and your Guide did a good job?
a) No, because one of us had collected significantly more toys than the other.
b) Yes, because both me and the Guide collected the same amount of toys.
c) Yes, because I had collected more toys than the Guide did.

4) How honest do you believe the Guide was? Did he guide you correctly?
a) Not at all.
b) Not many times.
c) Sometimes.
d) Most of the times.
e) Definitely.

5) How reliable do you believe the Guide was? Did he know where to go?
a) Not at all.
b) Not many times.
c) Sometimes.
d) Most of the times.
e) Definitely.

6) Did the Guide make mistakes at the provided directions?
a) Definitely.
b) Most of the times.
c) Sometimes.
d) Not many times.
e) Not at all.

7) Do you believe you were wrong NOT to follow the Guide's directions?
a) Not at all.
b) Not much, I was rarely wrong.
c) Sometimes.
d) Most of the times.
e) Definitely.
f) I always followed Guide's advice.

8) Do you believe that the Guide tried to misguide you on purpose, in order to collect more points?

a) Definitely. 
b) Most of the times.

c) Sometimes.

d) Not many times.

e) Not at all.

9) Do you believe that the Guide aimed for you to collect the same amount of toys as he did?
a) Definitely.
b) Most of the times.
c) Sometimes.
d) Not many times.
e) Not at all.

10) How often did you follow the Guide's exact directions?
a) Never.
b) Not many times.
c) Sometimes.
d) Most of the times.
e) Always.

11) How many times did you feel that you had right following the Guide's advice?
a) Never.
b) Not many times.
c) Sometimes.
d) Most of the times.
e) Always.
f) I never followed the Guide's advice.

12) How many times did you feel that you were right for NOT following guide's advice?
a) Always.
b) Most of the times.
c) Sometimes.
d) Not many times.
e) Never.
f) I always followed the Guide's advice.

13) If the exact same Guide proposed another run, would you choose to go with him again?
a) No way.
b) Maybe not.
c) Not sure.
d) Maybe yes.
e) Definitely.

14) How would you justify your answer in Question-13?
a) I know that I can't ever trust this Guide.
b) I am not sure if I can trust this Guide.
c) I know I can trust this Guide, but not always.
d) I know I can always trust this Guide. 